\title{
O PROCESSO DE ENSINO-APRENDIZAGEM NA EDUCAÇÃO FÍSICA ESCOLAR: UM OLHAR SOBRE O USO DE METODOLOGIAS ATIVAS NO ENSINO INFANTIL
}

\section{THE TEACHING-LEARNING PROCESS IN SCHOOL PHYSICAL EDUCATION: A LOOK AT THE USE OF ACTIVE METHODOLOGIES IN CHILD TEACHING}

\author{
Genilda Soares da Costa Feitosa \\ Graduada em Educação Física, Professora do Ensino Fundamental e de Jovens e \\ Adultos, Prefeitura Municipal de Conceição-PB, Brasil. \\ E-mail: genildaigs@hotmail.com \\ José Marciel Araújo Porcino \\ Especialista em Psicopedagogia Clínica e Institucional, Especialista em Saúde \\ Mental, Bacharelado em Psicologia e Licenciando Pedagogia, Brasil. \\ E-mail: leicram ap@hotmail.com
}

Recebido: 25/10/2020 - Aceito: 02/12/2020

\section{Resumo}

O objetivo dessa pesquisa é descrever o uso de metodologias ativas no processo de ensino e aprendizagem no âmbito da educação física escolar no ensino infantil. Para a constituição da presente pesquisa, foi utilizada como recurso metodológico para formulação do estudo, a revisão bibliográfica. Essa metodologia, oferecer ao pesquisador estratégias de conhecimentos já estuados, de modo a possibilitar a elaboração resolutiva frente à natureza do fenômeno estudado. Dando-lhe, as possíveis soluções diante de conteúdos relevantes. Os recursos didáticos e metodológicos assumem a corresponsabilidade no contexto da educação. Pois, as mudanças que ocorrem no mundo do ensino precisa adaptar a realidade e demanda inovação. E para isso ocorrer satisfatoriamente, a metodologia ativa vem para contribuí na busca de novos horizontes, de modo a dialogar no processo de ensinoaprendizagem. O uso da metodologia ativa implica articular ação planejada em espaço de discussão pedagógica e didática. Isto é, no que diz respeito a sua aplicabilidade. Nesse rol, a educação física escolar no âmbito do ensino e aprendizagem com criança, trata-se do conhecimento prévio que a criança tem dos espaços físicos e sua relação com o meio. Propomos, desta maneira, que a educação física escolar quando desenvolvida no seio da metodologia ativa, oferecem elementos estruturante de compreensão do corpo, cognição, afetivo, emocional, movimento, tamanho, altura e outros aspectos, que dão subsídios para o processo de aprendizagem. Essas questões constituem-se como meio ativo para desenvolver da criança.

Palavras-chave: criança; ensino; aprendizagem; desenvolvimento. 


\section{Abstract}

The objective of this research is to describe the use of active methodologies in the teaching and learning process in the context of school physical education in early childhood education. For the constitution of this research, the bibliographic review was used as a methodological resource for formulating the study. This methodology, to offer the researcher strategies of knowledge already studied, in order to allow the resolutive elaboration in face of the nature of the studied phenomenon. Giving you, possible solutions to relevant content. Didactic and methodological resources assume coresponsibility in the context of education. For, the changes that occur in the world of education need to adapt to reality and demand innovation. And for this to occur satisfactorily, the active methodology comes to contribute in the search for new horizons, in order to dialogue in the teaching-learning process. The use of active methodology implies articulating planned action in a pedagogical and didactic discussion space. That is, with regard to its applicability. In this role, school physical education in the context of teaching and learning with children, is the child's previous knowledge of physical spaces and their relationship with the environment. We propose, therefore, that school physical education, when developed within the active methodology, offer structural elements of body understanding, cognition, affective, emotional, movement, size, height and other aspects, which provide subsidies for thelearning process. These issues constitute an active means for the child'sdevelopment.

Keywords: child; teaching; learning; development.

\section{Introdução}

A introdução expõe o tema do artigo, relaciona-o com a literatura consultada, apresenta os objetivos e a finalidade do trabalho, definições, hipóteses e a justificativa da escolha do tema. Trata-se do elemento explicativo do autor para o leitor. "Não se aconselha a inclusão de ilustrações, tabelas e gráficos na introdução". (FRANÇA, 2008, p. 65)

O uso de metodologia ativa é algo novo no processo de ensino-aprendizagem e, provoca estranheza e desafios na sua aplicabilidade. Acredita-se ainda, que muitos profissionais de modo geral, não dispõem desse recurso metodológico e didático como ferramenta inovadora no ensino infantil. E a educação física no âmbito escolar, precisa acompanhar, ou adequa-se a essa inovação no intuito de propor e oferecer um ensino de qualidade capaz de despertar a curiosidade do aluno sobre os fenômenos do 
funcionamento do corpo e sua interface com os aspectos do meio ao qual estar inserido.

De tal modo que essas implicações podem causar ou tornar em dilema problemático na busca desses recursos enquanto instrumentos de trabalho do profissional da educação física escolar. Diante desse fenômeno, isso implica em desvendar descritivamente o que existe de mais atual no diz respeito ao uso de metodologia ativa. Considerando assim, essas dificuldades, observa-se que um dos meio possíveis nos dias atuais dentro da perspectiva do ensino-aprendizagem da educação física escolar no cenário infantil. $\mathrm{E}$ o uso de novas ferramentas pedagógicas.

Assim, dessa forma, enfatizando o uso de metodologia ativa no processo de ensino-aprendizagem da educação física escolar no âmbito infantil. Emergiram os seguintes questionamentos de como o uso de metodologia ativa pode auxiliar no manejo da educação física escolar aos olhos do processo de ensino-aprendizagem no ensino infantil e como pode contribui para o desenvolvimento de aprendizagem do aluno?

A importância do uso de metodologia ativa no processo de ensinoaprendizagem a luz do pensamento crítico, analítico e reflexivo da educação física escolar, é oportunizar ao aluno descobertas. E é essencialmente no ensino infantil que a criança vislumbra de conhecimento sobre o mundo e sua percepção ao qual pertence. Deste modo, os recursos didáticos e metodológicos ancorado em metodologias ativas, leva ao discente a capacidade em captar o que o rodeia.

Essa dimensão faz-se necessária nos dias atuais. No qual, nota-se que o mundo se apresenta dinâmico, objetivo e rápido diante das configurações provocadas por transformações e mudanças constantes. As quais podem ser observadas, que na maioria das vezes, os profissionais da educação em geral, e até mesmo as pessoas, não sabem lidar com essas situações, o melhor, o novo. O que ocorre, é que no âmbito escolar o uso de metodologia ativa no ensino infantil é algo novo.

Nesse sentido, falar sobre essa temática trata-se de um desafio que nos remete a pesquisar e descrever como o profissional de educação física na área escolar pode atuar conforme o uso de metodologia ativa no processo de ensino-aprendizagem. Com isso, a educação física manejada por esse eminente técnico, ganha notoriedade nesse 
campo de atuação. Por isso, o profissional tende-se adquirir novas competências mediante a busca de arcabouços teóricos que podem subsidiar as novas práticas da educação física infantil. Assim, possibilitando o diálogo tecnicamente dinâmico com aluno, de modo a promover oportunidades de aprendizagens.

Sendo assim, o conhecimento proposto por essa abordagem deve estar em consonância com o que é contemporâneo, para que a escola, o aluno e a sociedade disponham de uma aprendizagem que propicie ao desenvolvimento integral. O objetivo dessa pesquisa é descrever o uso de metodologias ativas no processo de ensinoaprendizagem no âmbito da educação física escolar no ensino infantil, conforme os métodos da didática do profissional da educação física. Espera-se assim, implicar numa atuação dinâmica e laboral no que diz respeito às ações dessa ciência.

Assim, dessa forma, a presente pesquisa se torna relevante ao descrever os elementos práticos da educação física escolar no ensino infantil. Uma vez que explora o que é de mais atual e significativo nesse campo. Ainda, o estudo pode contribuir para atuação dos profissionais da educação física escolar.

Para a constituição da presente pesquisa, foi utilizada como recurso metodológico para formulação do estudo, a revisão bibliográfica. Nesse contexto, observa-se que a pesquisa qualitativa é um meio de procedimento para coleta de dados. Na qual busca explicar os fenômenos do problema de pesquisa.

Nessa configuração, Gil (2002) corrobora que essa metodologia de pesquisa, tende-se a esclarecer, justamente o problema de estudo invocado. Podendo assim, oferecer ao pesquisador estratégias de conhecimentos já estuados, de modo a possibilitar a elaboração resolutiva frente à natureza do fenômeno estudado. DandoIhe, as possíveis soluções diante de conteúdos relevantes.

Para a composição do tratamento descritivo dos possíveis achados na pesquisa. Ressalta-se que, serão explorados a partir de estudos já abordados. Isto significa dizer, que, consistirá na busca de resultados de revisão de literatura. De forma que, a descrição compreensiva dessa pesquisa dar-se-á sobre o uso de metodologia ativa no processo de ensino-aprendizagem da educação física escolar no âmbito infantil.

O processo metodológico que será utilizado para o desenvolvimento deste estudo, dar-se-á ainda, por meio de levantamento de materiais fundamentados em 
bancos de dados confiáveis, validos e fidedignos. Assim, dessa forma, serão buscados nos bancos de dados indexados Scielo, Medline, Plataforma CAPES e google acadêmico, através de artigos científicos, monografias, teses, dissertações e livros.

Para utilização dos artigos científicos, monografia, tese e dissertações a rigor. Foram prefaciados por critérios de inclusão, de maneira que artigos científicos, monografia, tese e dissertações serão abordados em consonância a contextualização do objeto e dos objetivos da pesquisa, tomando-se como base as seguintes palavraschave: educação física e o uso de metodologia ativa, metodologia ativa no ensino infantil, a importância do uso de metodologia ativa na prática da educação física infantil, o processo do ensino-aprendizagem diante do uso de metodologia ativa.

Dialogando assim com essa perspectiva, Sampieri, Collado e Lucio (2013) enfatizam que o ponto de vista da revisão de literatura "consiste em detectar, consultar e obter a bibliografia e outras matérias úteis para propósitos do estudo, dos quais extraímos e sintetizamos informações relevante e necessária para o problema da

pesquisa." (SAMPIERI; COLLADO; LUCIO, 2013, p. 76).

Esses descritores foram buscados em artigos científicos, monografia, tese e dissertações em português com limite temporal definido pelo período compreendido entre 2008 a 2020. Ainda sendo aberto sem limite de tempo para livros de relevo na área e artigo com finalidade ao tema.

\section{Compreendendo o processo didático e metodológico do uso de metodologia ativa}

A aprendizagem é inerente ao ser humano conforme as suas particularidades, potencialidades e possibilidades ancoradas no manejo do ensino e aprendizagem que são construídas e reconstruídas a luz da necessidade do contexto. E a didática emerge como recurso metodológico essencial na vida do professor-mediadorfacilitador (VIOTTO FILHO, PONCE; ALMEIDA, 2009).

Nesse sentido, os recursos didáticos e metodológicos assumem a corresponsabilidade no contexto da educação. Pois, as mudanças que ocorrem no mundo do ensino precisa adaptar a realidade e demanda inovação. E para isso ocorrer satisfatoriamente, a metodologia ativa vem para contribuí na busca de novos horizontes, de modo a dialogar no processo de ensino-aprendizagem. 
Nesse discurso, conforme Malheiros (2019, p. 157) compreende-se como metodologia ativa no campo da educação "a inserção do aluno como agente protagonista de seu processo de construção do conhecimento". Ou seja, cabe ao professor torna mediador e facilitador nesse manejo.

Em função dessa prática, a educação física escolar na área infantil, exerce importante papel no desenvolvimento. Assim, ao propor essa metodologia de ensinoaprendizagem na educação infantil, a criança cada vez mais despertará o senso crítico de autonomia e de responsabilidade. Vale ressaltar que esse trabalho com a criança, deve ser elaborado ludicamente na prática da educação física.

O profissional da educação física escolar deve proporcionar situações lúdicas para que a criança em sala de aula e/ou em espaço da educação física desenvolva suas habilidades psico-motoras, cognitiva, afetiva, emocional e ética. Uma vez que a metodologia ativa vislumbra o exercício do protagonismo (MALHEIROS, 2019). Assim, a criança encontrará suas próprias respostas em busca de novos conhecimentos.

Nesta Perspectiva, essa metodologia educacional aborda a essência do ensino e aprendizagem no sentido formar, emancipar e situar as pessoas para a vida. Dessa forma, a educação física escolar considera o universo da criança como elemento

imprescindível na construção do corpo, caráter e dos valores humanos.

\section{Descrição do uso de metodologias ativas no processo de ensino-prendizagem no âmbito da educação física escolar no ensino infantil}

O uso da metodologia ativa implica articular ação planejada em espaço de discussão pedagógica e didática. Isto é, no que diz respeito a sua aplicabilidade. Nesse rol, a educação física escolar no âmbito do ensino e aprendizagem com criança, trata-se do conhecimento prévio que a criança tem dos espaços físicos e sua relação com o meio (VIOTTO FILHO, PONCE ; ALMEIDA, 2009).

Corroborando com essa visão, Lopes, DE Aquino Filho e Amaral (2019) consideram que as metodologias ativas trazem:

As metodologias ativas trazem o estudante para o centro do processo educativo, aumentando sua responsabilidade em relação à sua formação. 


\begin{abstract}
Portanto, o papel do professor também sofre mudanças, ele fica encarregado de apresentar o mundo ao estudante e, ao mesmo tempo, deixá-lo caminhar sozinho. Considerando-se um mundo em constante mudança, o ensino tradicional com a meta de transmitir conhecimentos perde espaço, pois o perfil do profissional exigido pelo mercado de trabalho passa a valorizar não só os conhecimentos técnicos, mas também habilidades de comunicação, relacionamento interpessoal, postura, entre outras.
\end{abstract}

Nesse sentido, podemos destacar que uso desse manejo em criança diante do saber-fazer da educação física escolar, encontra-se na exploração, interação e socialização da criança com meio, aonde ela ao poucos vai descobrindo e aprendendo sobre o seu entorno. Além disso, a criança vai associando e assimilando a construção do seu conhecimento (VIOTTO FILHO, PONCE; ALMEIDA, 2009).

Para tal atividade, o profissional de educação física; o professor habilitado visa facilitar e mediar atividades físicas exitosas com a realidade cognitiva, afetiva, emocional e psicomotora da criança e de suas relações com o meio. Demonstra-se assim, para isso, a necessidade de planejar, elaborar e executar metodologia ativa que der subsídios à criança a pensar, sentir e agir satisfatoriamente sobre o contexto onde estar inserida (GHIRALDELLI, 1991; LOPES, DE AQUINO FILHO; AMARAL, 2019).

Assim, dessa forma, elencarmos que atividades físicas como: princípio da experimentação, a reprodução de modelo e o ensino direto, despertam na criança o senso crítico, reflexivo, empático, cooperatividade, autonomia, corresponsabilidade, respeito e harmonia (MARANTE; DOS SANTOS, 2008). Percebe-se que, isso promove a interação e a socialização de todos os envolvidos.

A partir dessas implicações, observa-se que os saberes, destacados por Marante e Dos Santos (2008, p.74) enfatizam que cada conceito deve ser exercido seguindo três princípios básicos:

-O princípio da experimentação: em que os alunos vivenciam a tarefa proposta individualmente, realizando tentativas pessoais mediante orientação mais geral, e não específica. • A reprodução de modelos: quando cabe aos alunos a observação para, em seguida, construir o seu próprio modelo mental para realizar a tarefa solicitada. - O ensino direto: por parte do professor ou de outros alunos: mostra-se exatamente como o aluno deverá atuar, dirigindo a prática dele. (MARANTE \& DOS SANTOS, 2008, p.74). 
Neste direcionamento, promover atividades lúdicas no âmbito da educação física infantil é postular o desenvolvimento humano. Pois, associar às brincadeiras as práticas da educação física escolar, torna-se fundamento preciso de conexão da criança com o seu corpo, ambiente, onde as experiências no ato de brincar possibilitam a interação e aprendizagem por meio do contato, do olhar, correr, a pontar, dançar, saltar, nadar e jogar. Isto porque, envolve um método ativo estabelecido entre o aluno-professor (GRESPAN, 2016; GEWEHR, 2016; COLLIER; DE SOUSA, 2017).

Nesta perspectiva, a criança deixa de ser vista como uma ferramenta e/ ou objeto passivo e, passa a ser de direito uma pessoa ativa, que desde cedo constrói sua aprendizagem. E é nessa dinâmica que o profissional de educação física escolar, visa contemplar o desenvolvimento humano na fase infantil (PEREIRA; DA SILVA, 2018).

Corroborando com essa perspectiva, Neira $(2011$, p.5) Esclarece que:

\footnotetext{
À Educação Física cabe proporcionar situações em que estudantes analisem o chamado patrimônio corporal. Seu papel é investigar como os grupos sociais se expressam pelos movimentos, criando esportes, brincadeiras, lutas, ginásticas e danças, entender as condições que inspiram essas situações e experimentá-las, refletindo sobre quais alternativas e alterações são necessárias para vivenciá-las no espaço escolar e fora dele. Em termos práticos, trata-se de interpretar a gestualidade presente nessas manifestações, reproduzi-la, transformá-la e reiventá-la durante as aulas. (NEIRA; 2011, p.5).
}

Diante do exposto, percebe-se a importância da valorização da prática da educação física escolar. Isso porque, a metodologia ativa dar condições ao profissional expressar, criar, desenvolver e aplicar os recursos ativos ancorados no saber da educação física escolar, considerando e contextualizando o desenvolvimento infantil (LOVATO, MICHELOTT; DA SILVA LORETO, 2018; NETO, 2009).

Por isso é fundamental que o profissional de educação física no âmbito escolar, promova encontros, onde as crianças possam: sentir, pensar e agir frente ao contexto oferecido. Além disso, também favoreça situações desafiadoras próximas a realidade cognitiva, afetiva, emocional, psicomotoras. Ou seja, mediar ações práticas que considere as reais necessidades das crianças implica em dar oportunidade para se 
expressar, de modo que ela possa sentir ativa no processo de aprender (LOVATO, MICHELOTT; DA SILVA LORETO, 2018; NETO, 2009).

Essa ação permite ao educador, de modo geral, emancipar as conjunturas corporais, expressões faciais e gestuais. Pois, é através dessa dinâmica ativa que a criança começa a inserir, socializar e compartilhar de um saber com as outras crianças (GRESPAN, 2016; GEWEHR, 2016; COLLIER; DE SOUSA, 2017).

Considerando essas vivências, Neira $(2011$, p.5) nos propõe que:

A vivência de qualquer manifestação corporal na escola exige reflexão e adaptação, visando a torná-la mais interessante e próxima aos alunos. Afinal, cada grupo dança, joga e luta do seu jeito. Não fosse assim, a variedade não seria tão ampla.

Além de dar todas essas oportunidades de manifestações ao aluno por meio ativo, cabe também ao profissional recolher o máximo de informações sobre seus alunos, através de diálogos, conversas, das próprias manifestações corporal, gestuais e faciais que são emitidas pelos alunos nesse processo. Dessa forma, o profissional de educação física escolar, além dessas atribuições, colabora no desenvolvimento e a realização do aprendiz (GRESPAN, 2016; GEWEHR, 2016; COLLIER; DE SOUSA, 2017).

De outra forma, observa-se que nesse campo, também, pode ser explorado por múltiplos recursos de natureza ativa. Nessa conjuntura, Neira (2011, p.5) enfatiza que:

Por exemplos, um projeto que aborde uma dança contemporânea não se restringe a coreografar e repetir. Observar os gestos e estudar as letras para entender o que se está dizendo é fundamental. Compará-las com outros estilos, conhecer suas histórias, convidar dançarinos e assistir a vídeos poderão ajudar a desconstruir preconceitos e ampliar a repertório da turma. (NEIRA; 2011, p.5)

Diante do exposto, é notório que o profissional de educação física escolar no ensino infantil, deve propor práticas lúdicas de caráter ativo seguido por sequencia didática do arcabouço teórico da educação física escolar em consonância com a realidade da criança. Onde essa atividade possa contemplar: o movimento do corpo, esporte, brincadeiras, jogos e competições na comunidade. Com isso, a criança ao adentrar nesse universo proposto pela metodologia ativa, sentirá viva e participativa no processo (LOVATO, MICHELOTT; DA SILVA LORETO, 2018; NETO, 2009). 
Vale ressaltar nesse cenário, que o profissional, também se faça presente nessa dialética de ensino e aprendizagem, de modo que conheça as possibilidades, potencialidades e limitações dos seus alunos. Com isso, o professor atuará conforme os aspectos compreendidos em seu entorno. Desta forma, a criança desenvolverá sua ação para aprendizagem (PEREIRA; DA SILVA, 2018).

\section{Considerações finais}

Abordar a metodologia ativa na educação infantil pautada na educação física escolar nos remete enquanto educadores olhar para criança como ser ativo construtor de aprendizagens. Essa prática possibilita ao profissional compreender as dimensões da criança frente ao processo de ensino e aprendizagem.

As atividades desenvolvidas e aplicadas na perspectiva da metodologia ativa tende-se a lançar a criança desafios lúdicos que possibilitam o alcançar resultados satisfatório referente ao contexto pessoal, coletivo e educacional. Essas ações, a priore, proe a criança a construir soluções diante das situações da vida.

Nesse tecer, nota-se que o profissional de educação física inserido no âmbito escolar, tem a condição de atuar conforme as ações ativas evidenciadas pelo método do ser ativo, onde a criança apresenta essa característica intrínseca. O professor por sua vez, faz a mediação dos recursos do meio em consonância com o desenvolvimento da criança.

Propomos, desta maneira, que a educação física escolar quando desenvolvida no seio da metodologia ativa, oferecem elementos estruturante de compreensão do corpo, cognição, afetivo, emocional, movimento, tamanho, altura e outros aspectos, que dão subsídios para o processo de aprendizagem. Essas questões constituem-se como meio ativo para desenvolver da criança.

Em outras palavras, o manejo da metodologia ativa defende o processo ativo da criança e seu entorno como um método acessível e real de se fazer acontecer no dia a dia da criança. A esse respeito, a criança carrega uma vida repleta de vivências e experiências, que por sua vez, podem ser explorada significativamente em sala de aula e/ ou em espaço da disciplina da educação física escolar. E isso torna preciso, 
pois, a criança é uma transcendência de um universo que precisa ser vivido, através das atividades físicas.

A escola deve reconhecer e adotar afetivamente na educação infantil atividades que ofereça a criança a descobrir o seu corpo, o espaço e os valores humanos, de modo que articule e socializem com a comunidade os princípios aprendidos nessa disciplina. Com isso, os recursos propostos no ato da metodologia ativa, proem a criança ir além conforme suas possibilidades e potencialidades. Cabendo ao profissional de educação física, fazer a mediação entre o meio-criançaaprendizagem.

Por fim, queremos que outros estudiosos da educação em geral, possam vislumbrar da metodologia ativa como recurso didático e, em especial o profissional da educação física escolar. Espera-se que esse estudo possa contribuí no campo da educação. E que outras pesquisadoras, contemplem a existência dessa ação nos dias atuais em prol do desenvolvimento humano.

\section{Referências}

COLLIER, Luciana Santos; DE SOUZA, Claudia Teresa Vieira. Metodologias ativas na formação do professor de educação física. Revista Práxis, v. 9, n. 18, 2017.

GEWEHR, Diógenes et al. Metodologias ativas de ensino e de aprendizagem: uma abordagem de iniciação à pesquisa. Ensino \& Pesquisa, v. 14, n. 01, 2016. GHIRALDELLI, Paulo. Educação física progressista. Edições Loyola, 1991.

GIL, Antônio Carlos. Como classificar as pesquisas? In. Como elaborar

projetos de pesquisa. - 4. Ed.-São Paulo: Atlas, 2002. p.42 GRESPAN, Marcia Regina. Educação física no ensino fundamental: primeiro ciclo. apirus Editora, 2016.

LOPES, Jefferson Campos; DE AQUINO FILHO, Gilmar Ferreira; AMARAL, Luiz Henrique. METODOLOGIAS ATIVAS NA EDUCAÇÃO FÍSICA-PROPOSTAS DE UTILIZAÇÃO NO PROCESSO DE ENSINO APRENDIZAGEM. ( 2019.). En línea: https://www.eumed.net/rev/atlante/2019/05/metodologias-ativas-educacao.html

LOVATO, Fabricio Luís; MICHELOTTI, Angela; DA SILVA LORETO, Elgion Lucio. Metodologias ativas de aprendizagem: uma breve revisão. Acta Scientiae, v. 20, n. 2, 2018. 
MARANTE, Wallace Oliveira; DOS SANTOS, Mário Cesário. Metodologia de ensino da educação física: reflexão e mudanças a partir da pesquisa ação. Revista Mackenzie de Educação Física e Esporte, v. 7, n. 2, 2008.

NEIRA, Marcos Garcia. Educação física além do esporte. Revista mundo jovem, fevereiro de 2011. Link para acesso: www.mundojovem.com.br.

NETO, Inácio Brandl; BRANDL, Carmem Elisa Henn. Um estudo dos métodos de ensino utilizados nas aulas de educação física nas séries iniciais do ensino

fundamental. Caderno de Educação Física e Esporte, v. 8, n. 14, p. 19-26, 2009.

PEREIRA, Zeni Terezinha Gonçalves; DA SILVA, Denise Quaresma. Metodologia ativa: Sala de aula invertida e suas práticas na educação básica. REICE: Revista Iberoamericana sobre Calidad, Eficacia y Cambio en Educación, v. 16, n. 4, p. 6378, 2018.

SAMPIERI, Roberto. Hornandez; COLLADO, Carlos. Fernandez; LUCIO, Pilar. Baptista. Metodologia de pesquisa. 5. ed. - Porto Alegre: Penso, 2013.p.76 VIOTTO FILHO, Irineu A. Tuim; PONCE, Rosiane de Fátima; ALMEIDA, Sandro Henrique Vieira de. As compreensões do humano para Skinner, Piaget, Vygotski e Wallon: pequena introdução às teorias e suas implicações na escola. Psicologia da Educação, n. 29, p. 27-55, 2009. 